Pak. j. sci. ind. res. Ser. B: biol. sci. 201255 (3) 129-137

\title{
A Study of Poisonous Plants of Islamabad Area, Pakistan
}

\author{
Saleem Ahmad \\ Pakistan Museum of Natural History, Garden Avenue, Islamabad, Pakistan \\ (received June 15, 2010; revised October 1, 2012; accepted October 8, 2012)
}

\begin{abstract}
Poisonous plants growing wild and cultivated in Islamabad area were studied. A total of 45 taxa belonging to 30 families are reported here from the study area. These include 6 trees, 12 shrubs and 27 herbs. Twenty species are found wild in the area, another 20 species are cultivated, while 5 species are found both cultivated and naturally occurring. Besides taxonomic details, poisonous parts, chemical constituents responsible for poisoning, and the human specific physiological effects of poisoning in relation to each plant are presented in a tabular format. The harm caused by these poisonous plants is often not serious, and is primarily restricted to gastrointestinal irritation or mild nervous system effects, that is curable. However, there have been cases of death resulting from the consumption of parts of highly poisonous plants in the area.
\end{abstract}

Keywords: poisonous plants, vegetation taxonomy, environment, Islamabad

\section{Introduction}

A strict definition of a poisonous plant is not easily constructed, since the boundaries between harmful and harmless plants are frequently blurred. A poisonous plant is usually defined as one whose consumption in a certain amount gives rise to abnormal or impaired functions in the human physiology (Cooper and Johnson, 1984; Lewis and Elvin-Lewis, 1977). These effects are due to the presence of certain toxic chemicals within a plant, which may be ingested, injected, absorbed or contacted through the skin. Some plants have evolved secondary metabolites through the course of evolution, which are not directly involved in their typical growth functions, but rather they serve a protective role for plant. For instance, presence of some of these substances makes a plant slightly to highly poisonous for animals, thus serving as a deterrent to herbivory.

Poisonous plants can be classified on the basis of the chemicals they possess such as alkaloids, glycosides (including saponins), nitrates, bitter principles, oxalates, tannins, phenols, and volatile oils. Alkaloids are the most important group of chemical bases that have an alkali-like reaction, with over 4000 distinct compounds that have been discovered to date. Nicotine, colchicine, morphine, ephedrine, and atropine (among others) are common alkaloids that are most familiar to the general public. These have a bitter taste and show pharmacological activity that often effect the gastrointestinal tract E-mail: drsais1@gmail.com and the central nervous system (Frohne and Pfander, 1984). Families like Amaryllidaceae, Apocynaceae, Buxaceae, Asteraceae, Euphorbiaceae, Fabacae, Liliaceae, Papaveraceae, Ranunculaceae and Solanaceae are particularly rich in alkaloids.

Glucosides and glycosides form a group of chemicals that upon splitting give rise to a carbohydrate and one or more other products called aglycones. Although many of these chemicals are not toxic, some cause poisoning by releasing toxic chemicals on hydrolysis (e.g. cyanide or hydrocyanic acid). The majority of cyanide poisoning is caused by species belonging to the Rosaceae, Fabaceae and Poaceae. The cyanogenic glucoside amygdalin is found in bitter almonds and commonly causes cyanide poisoning. Cardiac glycosides are known for their anti-arrhythmic effects on the heart as well as their high levels of toxicity, and are found in taxa such as foxglove (Digitalis spp.) and oleander (Nerium oleander L.). Bitter principles are neutral substances present in some Cucurbitaceae, Aloe, Cassia, Artemisia, etc. which have a nauseous, bitter taste and purgative action. Phenols are small molecules containing one or more phenolic group. They are the most widely distributed class of secondary metabolites with several thousand different compounds identified. Most of the phenols are known to have an antioxidant activity (Dimitrios, 2006).

Oxalates found in the form of oxalic acid and its salts are common in many plants but their abundance causes 
toxic effects, especially in members of the Oxalidaceae, Geraniaceae, Araceae and Polygonaceae. Nitrogenous compounds including certain proteins, peptides and amino acids also cause poisoning and are found in certain plants. Toxic proteins or toxalbumins have been found in Fabaceae, Euphorbiaceae, etc. and cause agglutination of the red blood corpuscles. Essential or volatile oils, which impart the characteristic odour in plants have sharp burning taste and can be toxic internally affecting the GIT and CNS. These are abundantly present in Lamiaceae, Asteraceae, Rutaceae, Apiaceae, Myrtaceae, etc. Tannins are non-nitrogenous derivatives having an astringent action, some of which are toxic if taken in large amount. These are common in many plants. Resins form a heterogeneous group of complex and variable chemical substances. Some of these cause poisoning due to their purgative or irritant properties as in certain species of the Cucurbitaceae, Convolvulaceae and Euphorbiaceae (Tampion, 1977; Nasir and Ali, 1970; Dymock et al., 1890-1893).

Islamabad is situated on the north eastern part of the Potohar plateau and is located between latitudes 33 ${ }^{\circ} 36^{\prime}$ ' and $33^{\circ} 49^{\prime} \mathrm{N}$ and longitudes $72^{\circ} 20^{\prime}$ ' and $73^{\circ} 24$ ' E. It covers an area of $382 \mathrm{~km}^{2}$ of undulating topography and the altitude varies from 503 to $610 \mathrm{~m}$. The mean maximum and minimum temperatures in the summer are $34.2{ }^{\circ} \mathrm{C}$ and $24.4^{\circ} \mathrm{C}$; those in winter are $16.7^{\circ} \mathrm{C}$ and $3.4^{\circ} \mathrm{C}$, respectively. Rainfall occurs in the monsoon season and winter, with the annual average being $1143 \mathrm{~mm}$. Rawal and Simli Dams are the main water reservoirs, and several small streams are running from north to south in this area. The original vegetation of the site is subtropical scrub forest type (Champion et al., 1965), which has been considerably modified by the introduction of large number of cultivated trees (Ahmad and Khattak, 2001). The flora of the area is an extension of the Mediterranean type (Stewart, 1957).

Among all the cities of Pakistan, Islamabad has the richest vegetation, both in terms of the total number of plants as well as the number of species. The green belts provide habitat for not only many cultivated taxa, but also for a large number of wild herbs and grasses which thrive throughout the seasons (Ahmad and Khattak, 2001). While most of these plants have a beneficial effect on the environment of the area, a few harmful species also get the chance to grow and proliferate. Because of their proximity with the population, they are certainly likely to come with human contact and may lead to poisoning if consumed out of inquisitiveness or a self-medication effort.

Some pertinent references on poisonous plants have been published in the USA and Europe (Connor, 1997; Cooper and Johnson, 1984; Frohne and Pfander, 1984; Tampion, 1977; Kingsbury, 1964). There has also been ample discussion of poisonous plants in several books and encyclopaedias dealing exclusively with medicinal plants (Heywood and Chant, 1982; Grieve, 1979; Stuart, 1979; Lewis, and Elvin-Lewis, 1977; Anderson, 1967). Likewise, regionally focused information on Indian poisonous plants have been provided in several Indian literature sources (Chopra et al., 1984, 1956; Pandey, 1984; Modi, 1945; Dymock, et al., 1890-1893). In contrast, only a few references are available on the specific poisonous plants of Pakistan (Baquar, 1989; Ikram and Hussain, 1978; Baquar and Tasnif, 1967).

\section{Materials and Methods}

Specimens of plants known to cause poisoning were collected from various areas of Islamabad during 20082009 and prepared following standard herbarium procedures. Specimens were identified with the help of floras and manuals (Polunin and Stainton, 1985; Willis and Airy Shaw, 1985; Stewart, 1972; Nasir and Ali, 1970; Hooker, 1875-1888). Voucher specimens were deposited in the Herbarium of the Pakistan Museum of Natural History (PMNH). Rare specimens were consulted in the Herbarium of Quaid-i-Azam University, Islamabad and National Herbarium Rawalpindi, Pakistan. All taxa were listed in tabular format, and include the following information: scientific, common, and local names, occurence, growth habit and duration, poisonous parts, chemicals constituents responsible for poisoning, and the human specific physiological effects of poisoning in relation to each plant.

\section{Results and Discussion}

The poisonous plants of Islamabad are summarized in Table 1. It gives knowledge of poisonous plants at a glance and severity of poison of each plant included in this list.

Yellow Oleander (Thevetia peruviana) was planted in gardens and roadsides in Islamabad for its attractive flowers. But, its fruit is poisonous, consumption has lead to multiple deaths. Lantana or Panch Phuli (Lantana camara) was planted as an ornamental bush in Islamabad, but has spread very much and formed 
Poisonous Plants of Islamabad

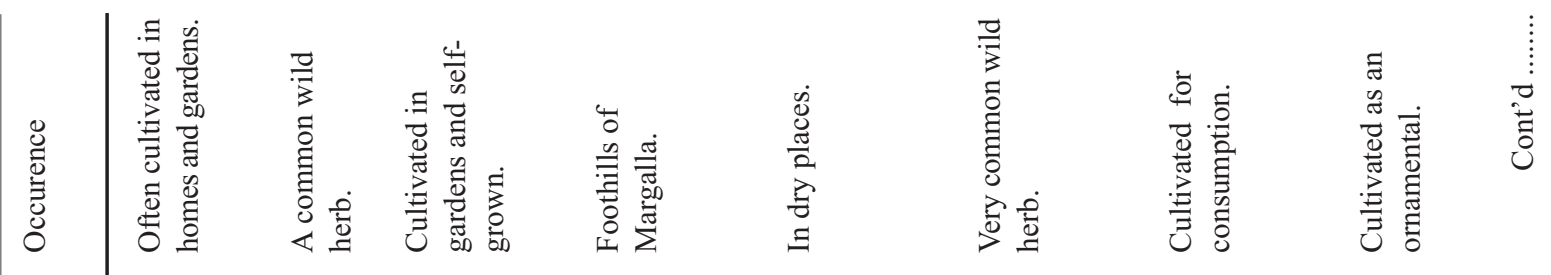
|In

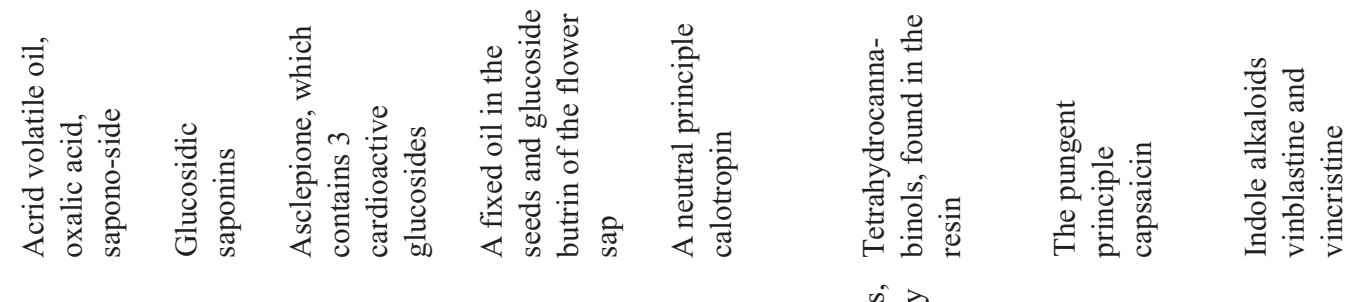

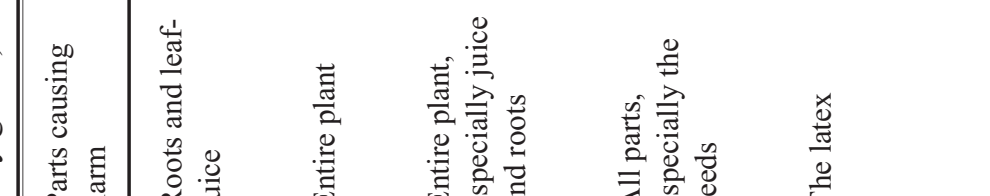

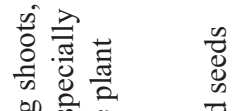

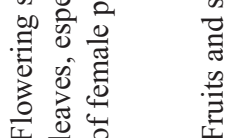
(1)

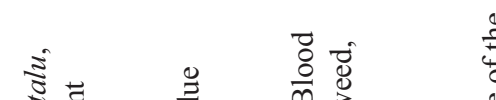

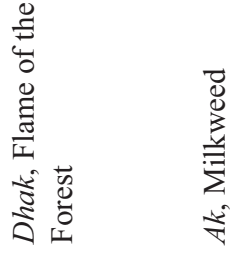

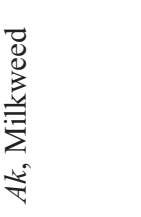

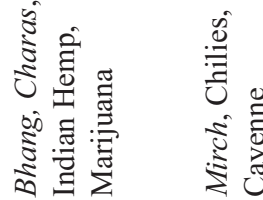

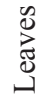

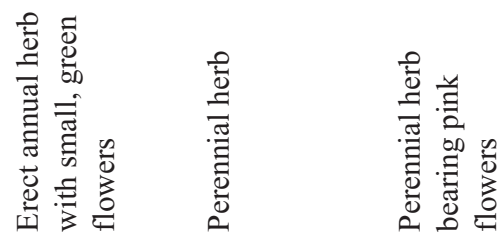

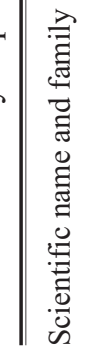

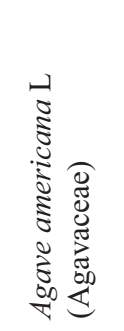

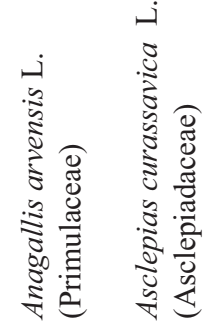

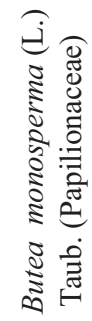

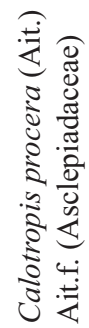

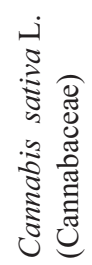

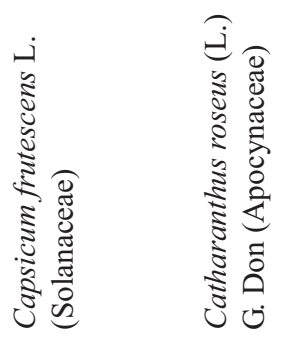



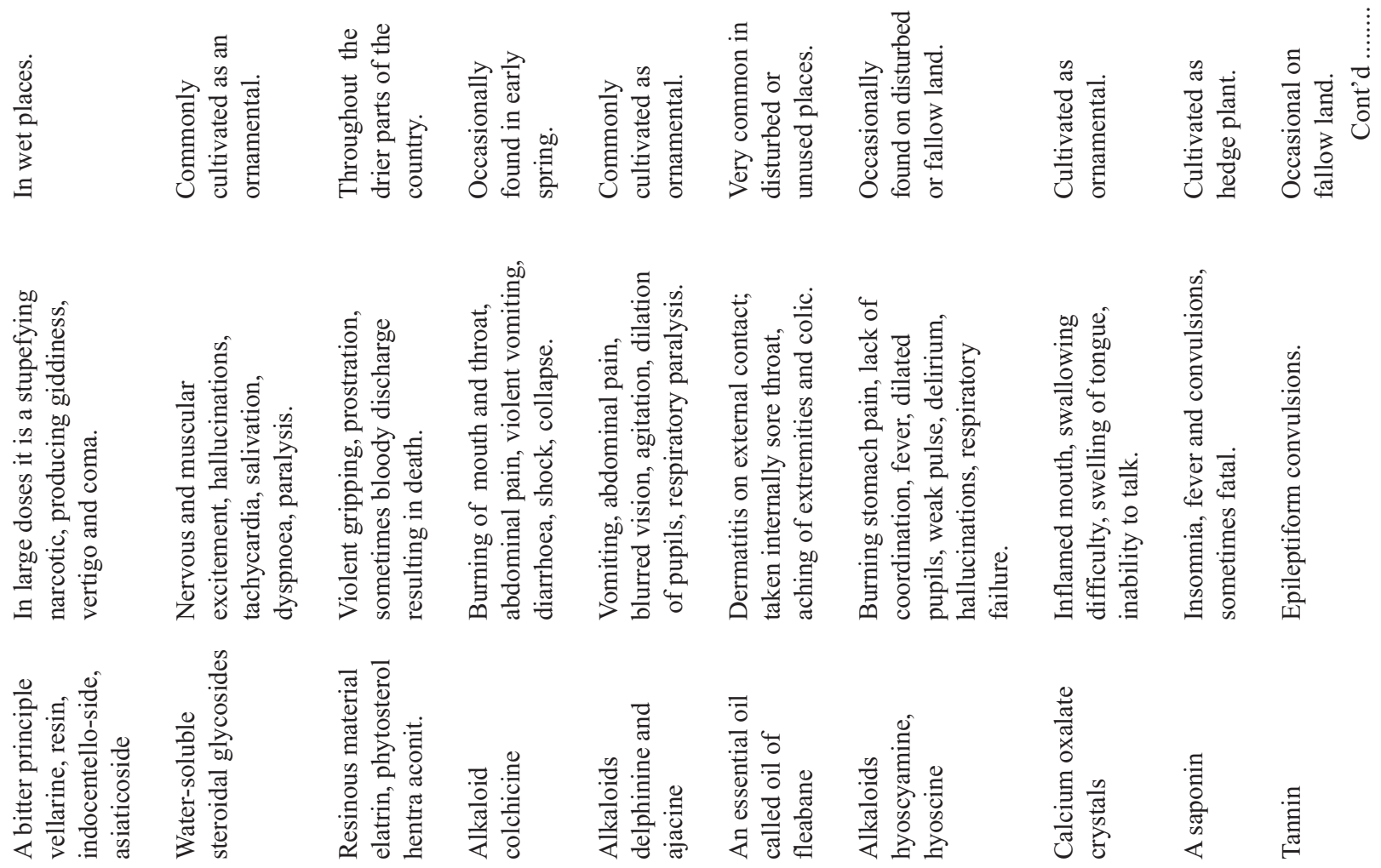

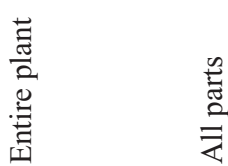

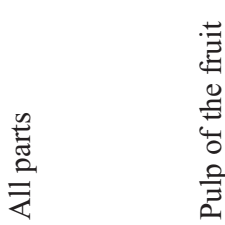

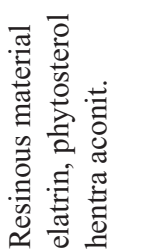

$\frac{0}{0}$
$\frac{0}{0}$
$\frac{\pi}{2}$
$\frac{0}{8}$

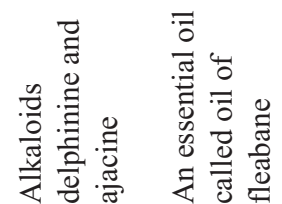

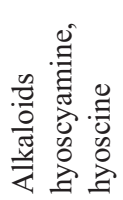

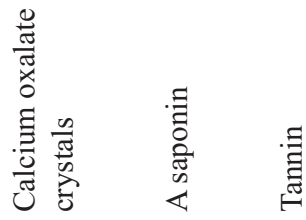

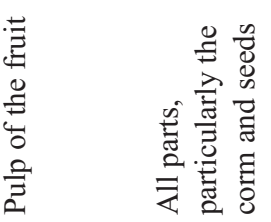

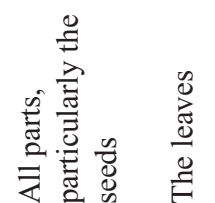

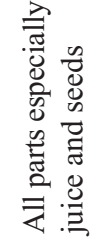

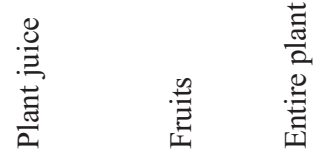

责

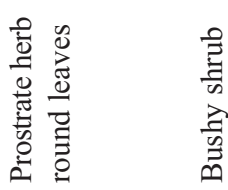

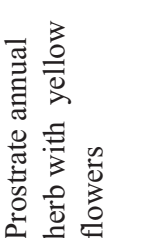

责察

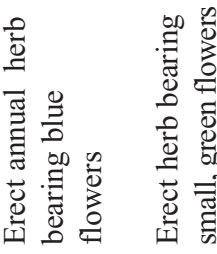

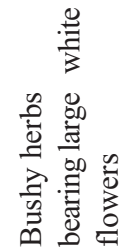

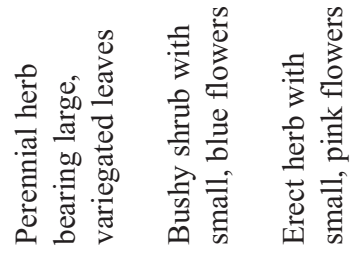

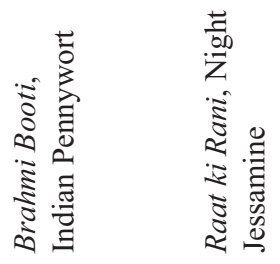

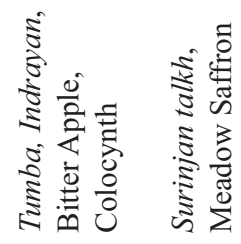

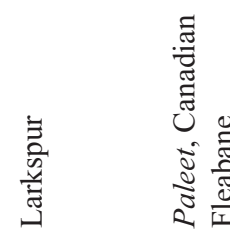

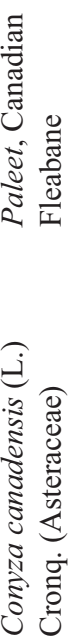

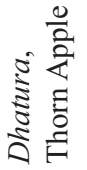

ठี
है
है

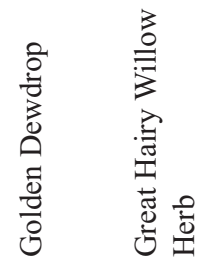

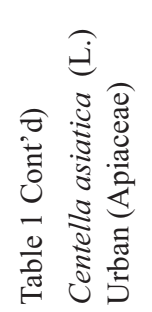
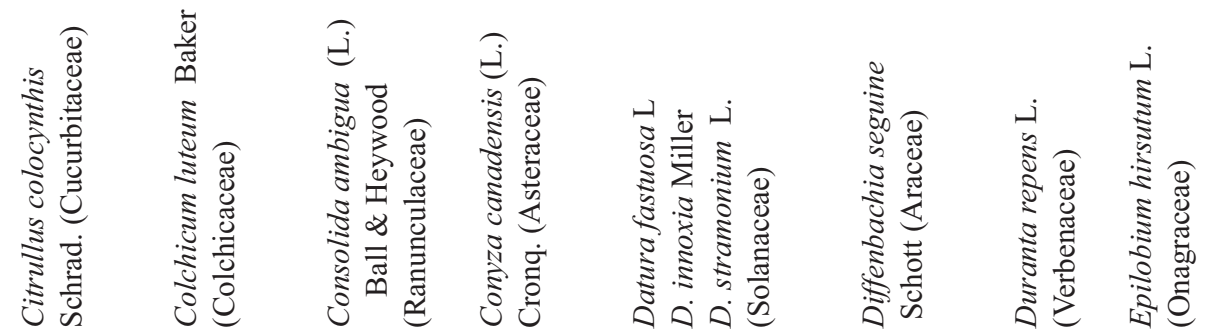


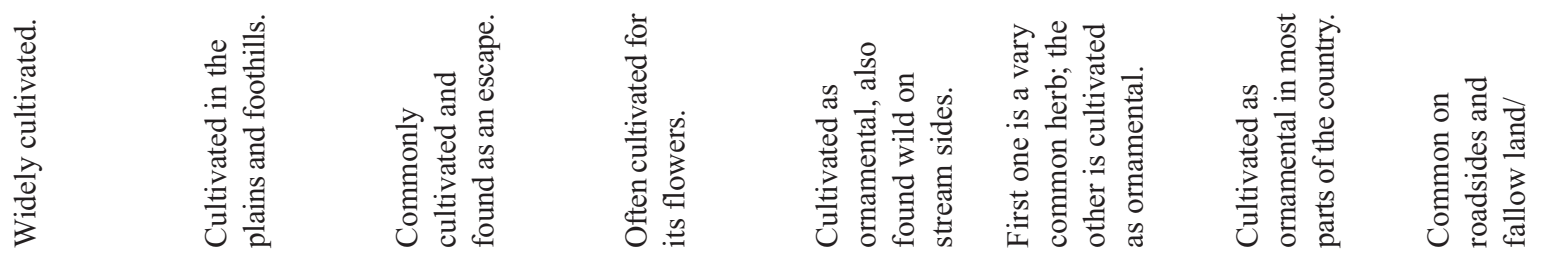
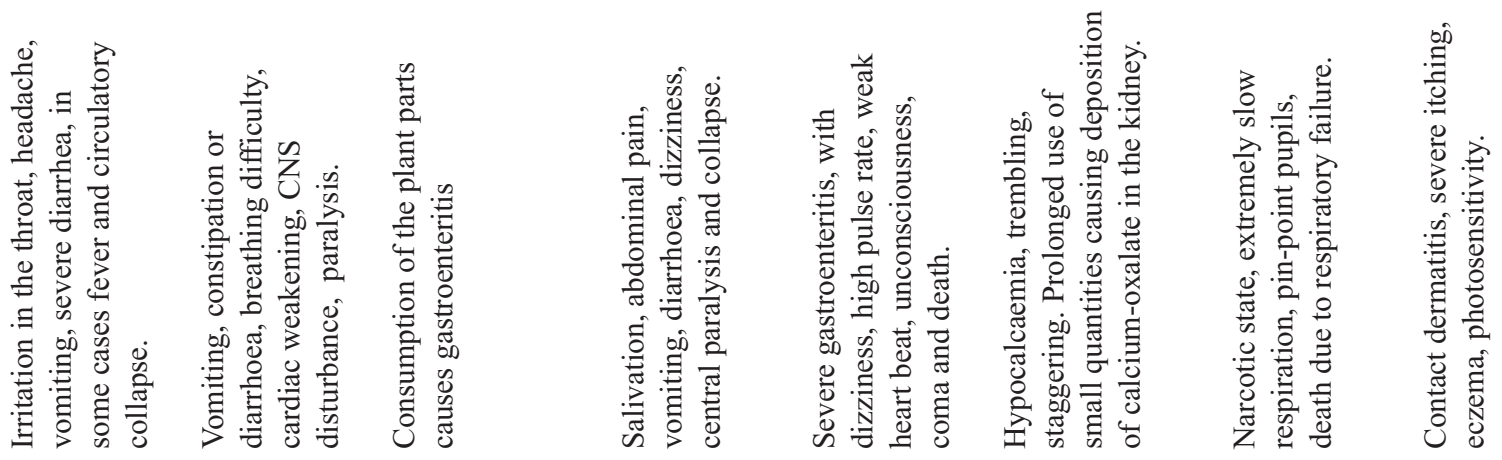

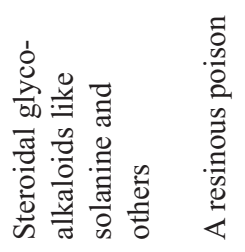
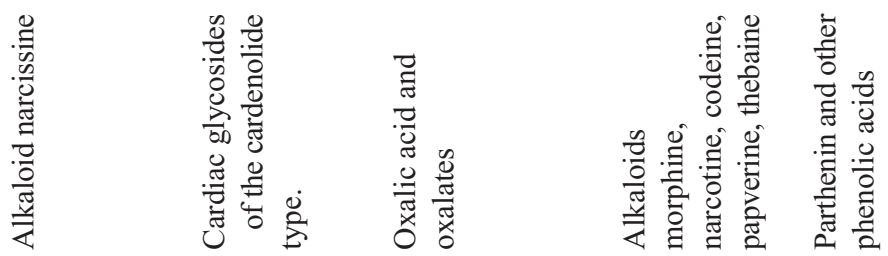

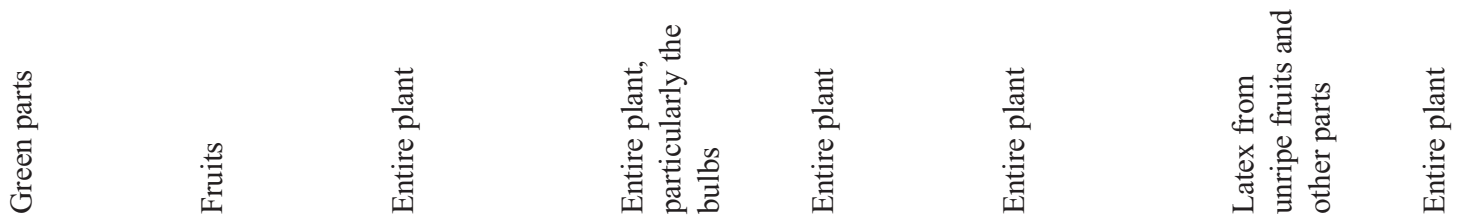

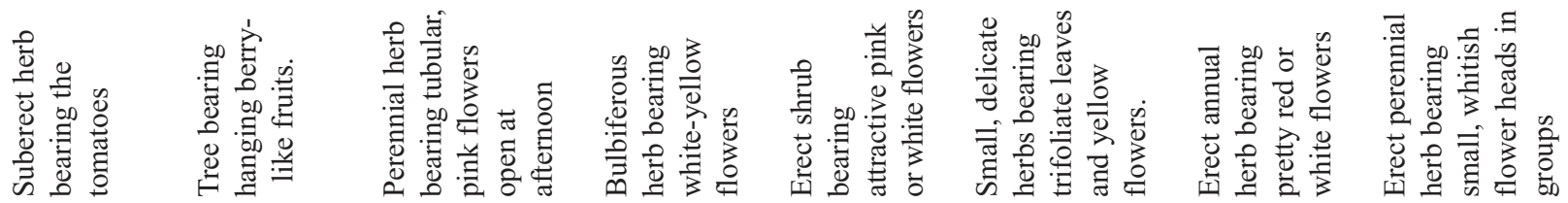

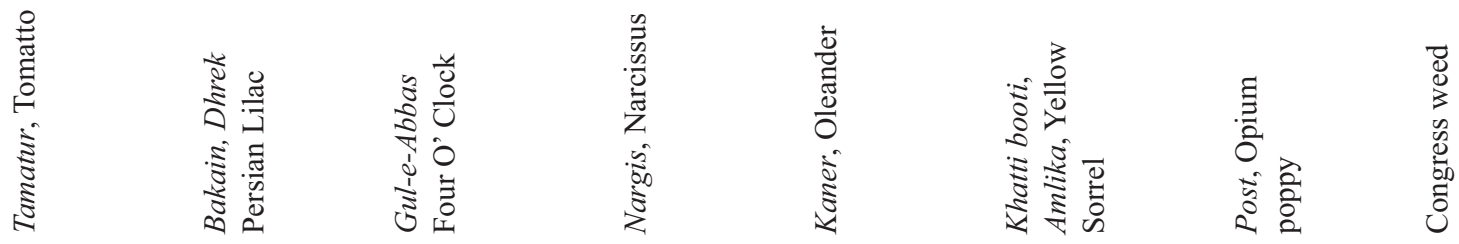

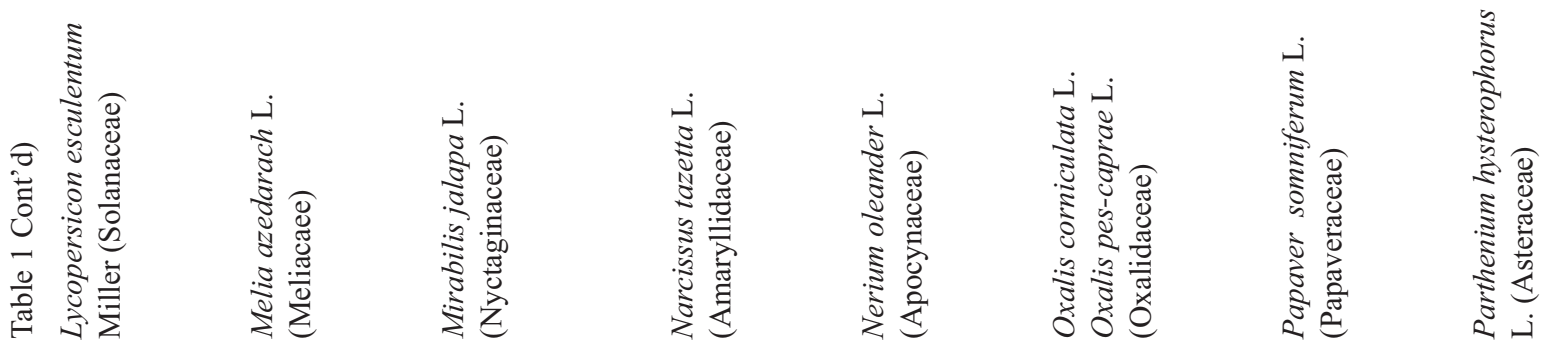



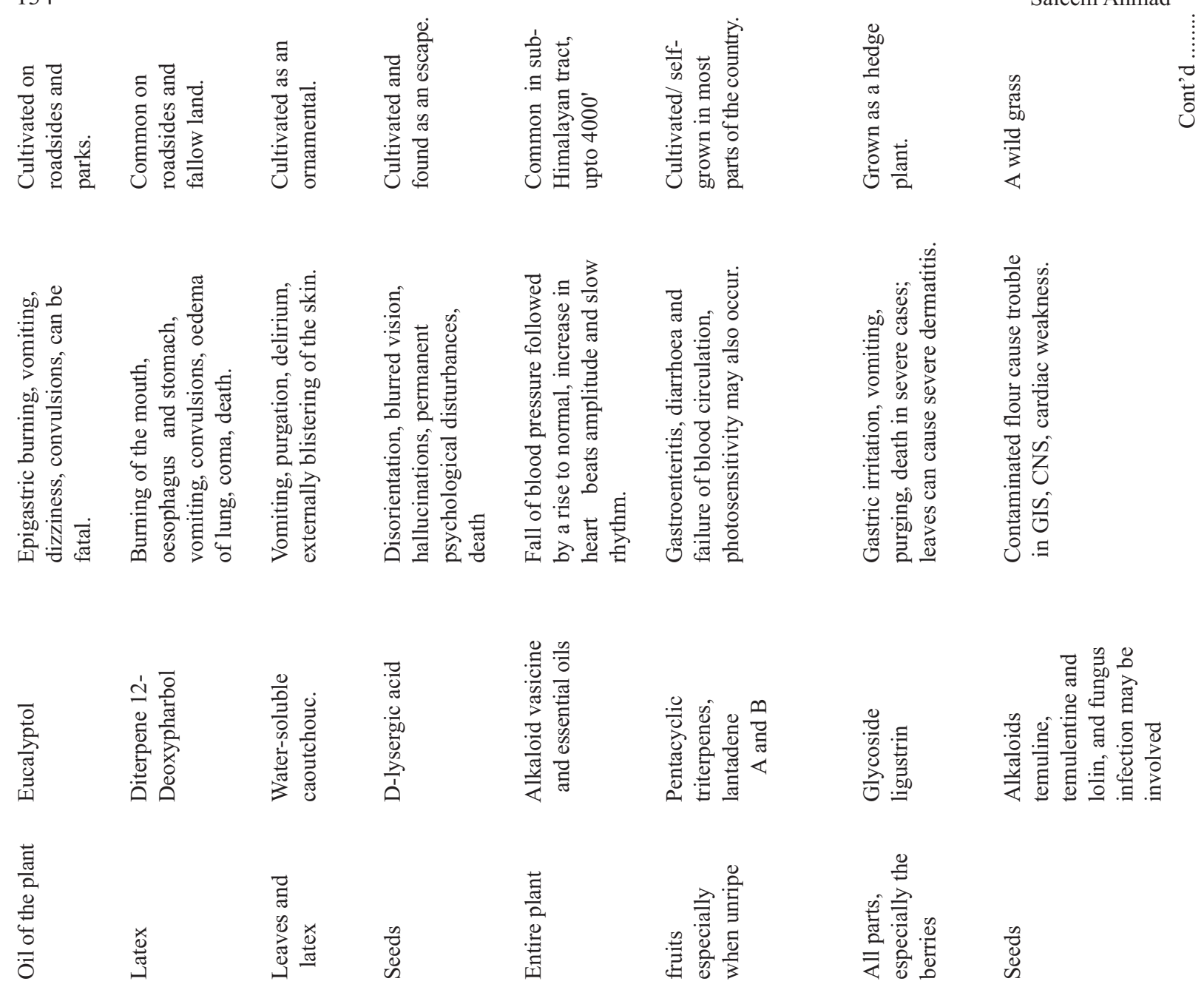

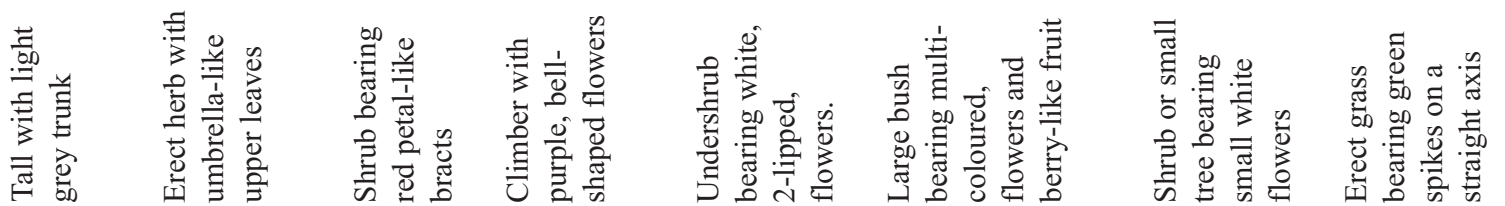

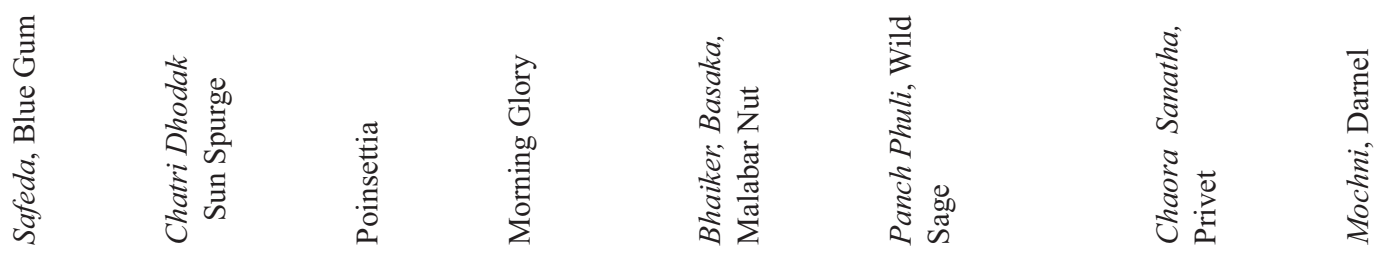

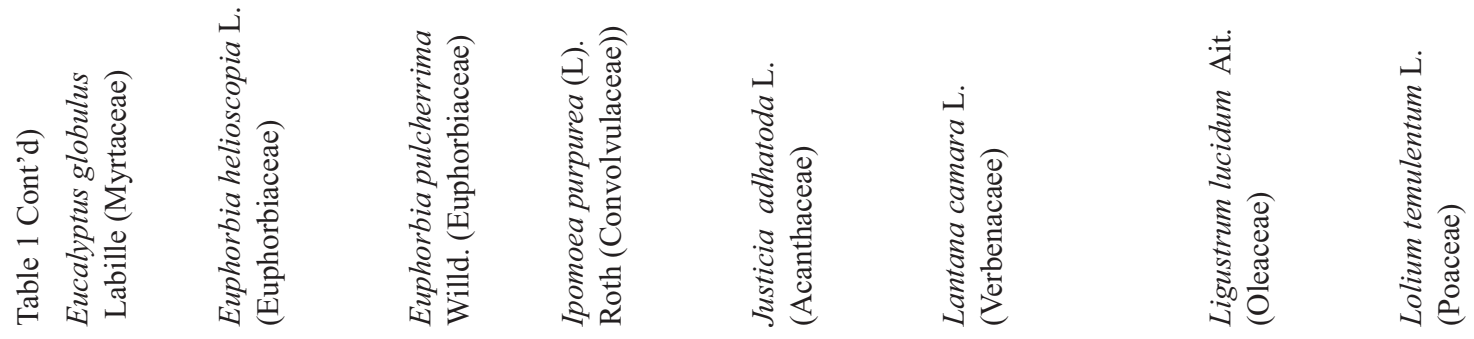


Poisonous Plants of Islamabad
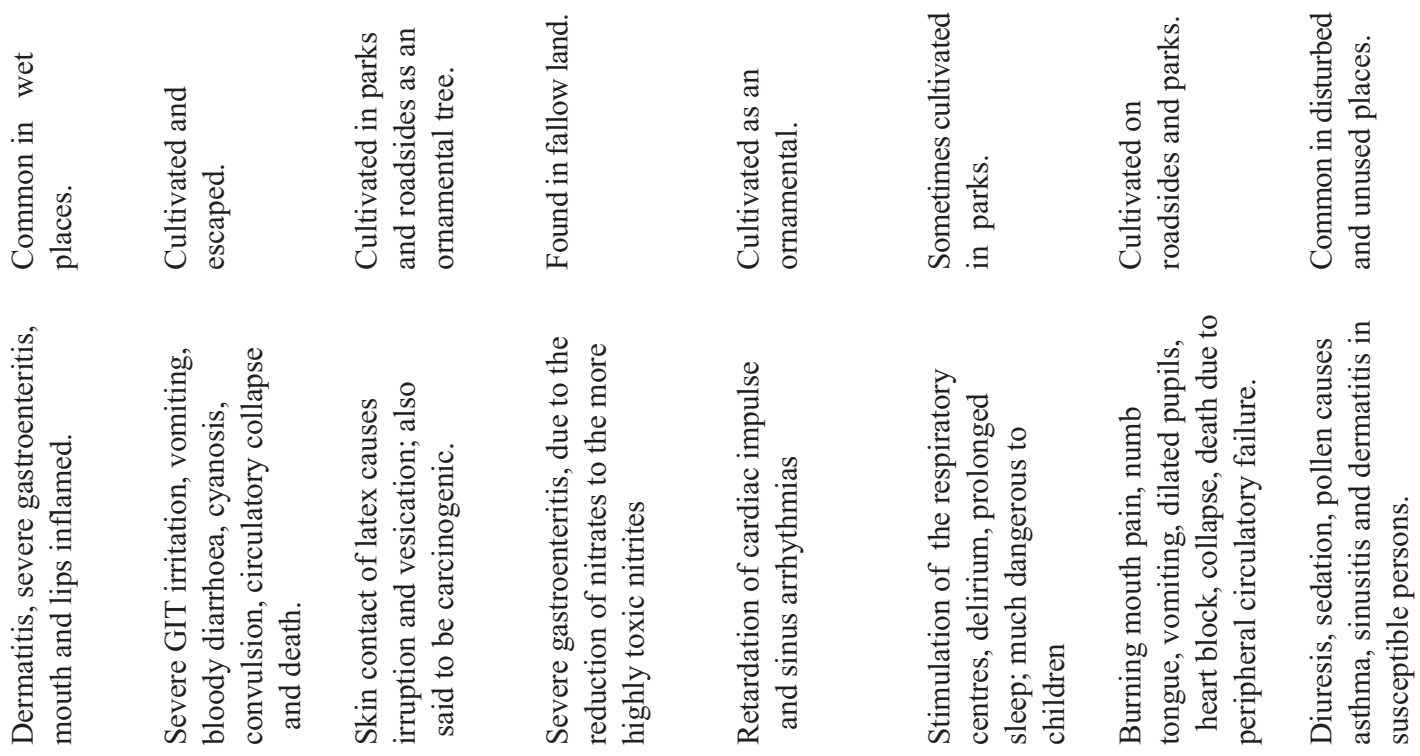

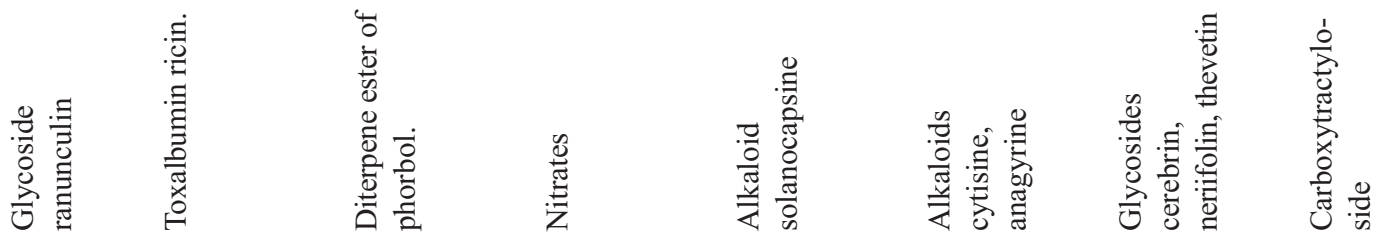

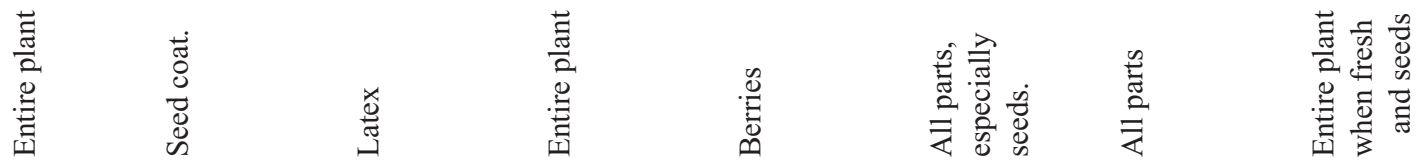

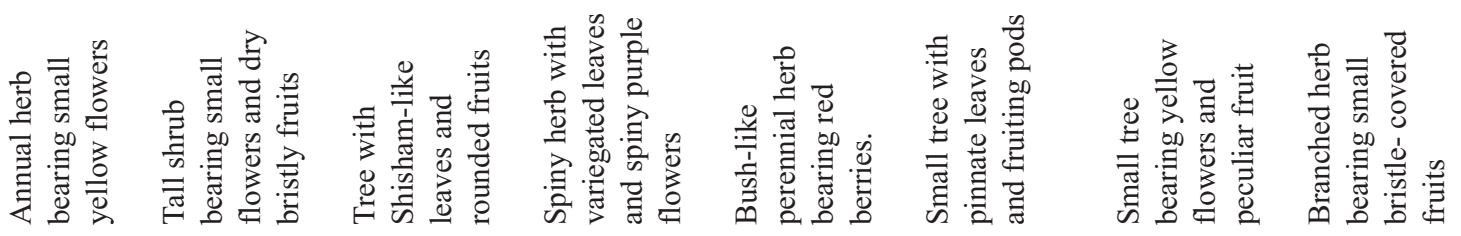

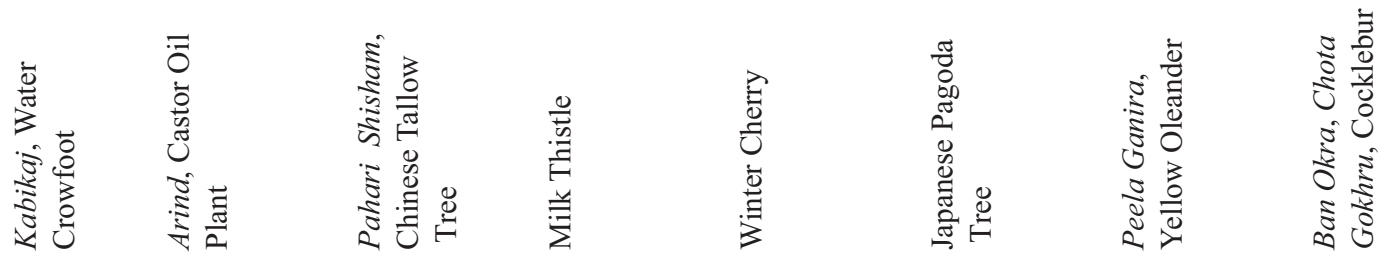

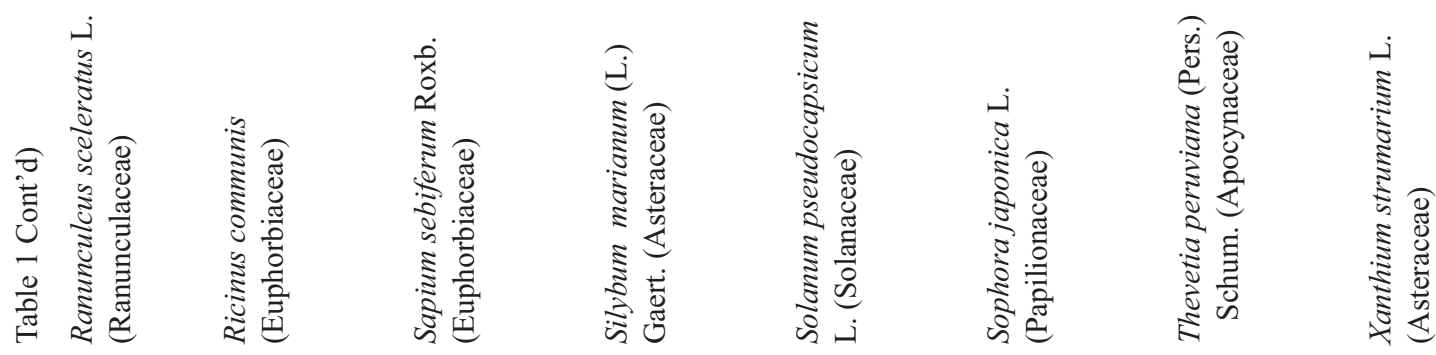


impenetrable thickets in waste places. Its ripe fruits are harmless and are eaten by people and also used in herbal medicine, but when unripe they can cause poisoning. Oleander (Nerium oleander) is quite common in parks and roadsides as it has quite beautiful floral display, but contains deadly toxins. Blood weed (Asclepias curassavica), Madagasar periwinkle (Catharanthus roseus), night jessamine (Cestrum nocturnum), Lakspur (Consolida ambigua), golden dewdrop (Duranta repens), Poinsettia (Euphorbia pulcherrima), morning glory (Ipomoea purpurea), Privet (Ligustrum lucidum), four O'clock (Mirabilis jalapa), opium poppy (Papaver somniferum) are commonly cultivated in parks and gardens.

The harm caused by these poisonous plants is often not serious, and is primarily restricted to gastrointestinal irritation or mild nervous system effects, which are usually cured by a physician. However, there have been cases of death resulting from consumption of parts of highly poisonous plants. For example, several young people have died in Islamabad after eating the odd looking fruit of the yellow oleander (Thevetia peruviana), leaves of night jessamine (Cestrum nocturnum) and oleander (Nerium oleander). Use of the narcotic Hemp (Cannabis sativa), which is common in this country, has led to death of a few addicts due to overdose (Chopra et al., 1984). Some of the poisonous plants like Butea, Calotropis, Centella, Datura, Solanum and Withania are used in herbal medicines in Pakistan (Nasir and Ali, 1970). The use of incorrectly prepared herbal medicines also cause poisoning, especially among rural people. Preparations for enhancing sexual performance are also commonly sold, which often contain extracts from toxic plants, animals constituents, and various minerals that cause harm to the uniformed users. Green vegetative parts of commonly used "vegetables", like potatoes (tubers) and tomatoes (berries) can lead to poisoning since few people are aware of their toxicity.

Of the various plant parts, the attractive-looking fruits of cultivated or wild plants cause poisoning more frequently and victims are often children. Fruits of black nightshade (Solanum nigrum) locally called 'Makoh' is a common roadside plant of Islamabad. Its ripe fruits are harmless and are often eaten by children. But its unripe fruits are toxic and if consumed in large numbers can be very harmful. Datura species are often seen in groups and are attractive because of their large, funnel-shaped white flowers. Its prickly fruits contain a large number of seeds that are used by
Hakims in anti-asthma preparations. But used alone, the seeds can cause poisoning with hallucinogenic effects or death. Leaves and/or stems of some plants are also consumed out of curiosity, which may cause poisoning (e.g. the stem of the commonly cultivated Diffenbachia causes severe inflammation if it comes in contact with the mouth).

It is important that people abstain from consuming any unconventional plant parts, even if they may not appear harmful. Children at home and in parks should be kept under watch and trained not to taste plant parts. In the event of ingestion and appearance of any undesirable symptom, the child should be taken to a hospital. As a preveitive measure, it is imperative that public awareness about the poisonous plants in ones vicinity be emphasized to prevent any unnecessary or even tragic events associated with local poisonous plants.

\section{References}

Ahmad, S., Khattak, Z. 2001. Quantitative studies on the vegetation of Islamabad. Pakistan Journal of Scientific and Industrial Research, 44: 279-285. Anderson, E. 1967. Plants, Man and Life, pp. 124-135, University of California Press, Berkley, USA.

Baquar, S.R.H. 1989. Medicinal and Poisonous Plants of Pakistan, 506 pp., Printas Karachi, Pakistan.

Baquar, S.R., Tasnif, M. 1967. Medicinal Plants of Southern West Pakistan, pp. 7-119, Pakistan Council of Scientific and Industrial Research, Karachi, Pakistan.

Champion, H.G., Seth, S.K., Khattak, G.M. 1965. Forest Types of Pakistan, pp.130-140, Pakistan Forest Institute, Peshawar, Pakistan.

Chopra, R.N., Badhwar, R.L., Ghosh, S. 1984. Poisonous Plants of India, vol.1, pp. 13-23, Academic Publishers, Jaipur, India.

Chopra, R.N., Nayar, S.L. Chopra, I.C. 1956. Glossary of Indian Medicinal Plants, pp. 13-63, Council of Scientific and Industrial Research, New Delhi, India.

Connor, H.E. 1997. The Poisonous Plants in New Zealand. E.C. Keating (ed), pp. 14-27, $2^{\text {nd }}$ edition. Government Printer, Wellignton, New Zealand.

Cooper, M.R., Johnson, A.W. 1984. Poisonous Plants in Britain and their Effects on Animals and Man. pp. 130-305. Her Majesty's Stationery Office, London, UK.

Dimitrios, B. 2006. Sources of natural phenolic antioxidants. Trends in Food Science \& Technology. 17: 505-512. 
Dymock, W., Warden, C.J.H., Hooper, D. 1890-1893. Pharmacographia Indica. vol. 1, pp. 59-81, Education Society's Press, Bombay, India.

Frohne, D. Pfander, H.J. 1984. A Colour Atlas of Poisonous Plants, pp. 113-291, Wolfe Publishing Ltd, London, UK.

Grieve, M.1979. A Modern Herbal. C.F. Level (ed.), pp. 170-171, Jonathan Cape, London, UK.

Heywood, V.H. Chant, S.R. 1982. Popular Encyclopedia of Plants, pp. 116-117, Cambridge University Press, UK.

Hooker, J.D. (ed.) 1875-1888. The Flora of British India. vols. 1, pp. 20-21, L. Reeve \& Co. Ltd. Ashford, Kent, UK.

Ikram, M., Hussain, S.F. 1978. Compendium of Medicinal Plants. 167 pp., Pakistan Council for Scientific and Industrial Research, Peshawar, Pakistan.

Kingsbury, J.M. 1964. Poisonous Plants of the United States and Canada. pp. 9-28, Prentice Hall, Englewood Cliffs, New Jersey, USA.

Lewis, W.H., Elvin-Lewis, M.P.F. 1977. Medical Botany: Plants Affecting Man's Health. pp. 11-62, John Wiley \& Sons, New York, USA.

Modi, N.J. 1945. Textbook of Medical Jurisprudence and Toxicology (First edition, 1920). Tripathy Ltd., Bombay, India.

Nasir, E., Ali, S.I., (eds.). 1970. Flora of West Pakistan/ Nos. 1-190, PARC, National Herbarium, Islamabad and Department of Botany, University of Karachi, Pakistan.

Pandey, B.P. 1984. Economic Botany. 476 pp., S. Chand \& Company Ltd., New Delhi, India.

Polunin, O., Stainton, A. 1985. Flowers of the Himalaya. vol. 1, pp. 11-391, Oxford University Press. Delhi, India.

Stewart, R.R. 1972. An Annotated Catalogue of the Vascular Plants of Pakistan and Kashmir. 1028 pp., Fakhri Printing Press, Karachi, Pakistan.

Stewart, R.R. 1957. The Flora of Rawalpindi District. Pakistan Journal of Forestry, 7: 240-300.

Stuart, M. 1979. The Encyclopedia of Herbs and Herbalism. 283 pp., Orbis Publishing Ltd., London, UK.

Tampion, J. 1977. Dangerous Plants, pp. 73-81. David and Charles Publication, Newton Abbot, London, UK.

Willis, J.C., Airy Shaw, H.K. 1985. A Dictionary of the Flowering Plants and Ferns. 1245 pp., $8^{\text {th }}$ edition, Cambridge University Press, UK. 